\title{
Effects of demersal trawling along the west coast of southern Africa: multivariate analysis of benthic assemblages
}

\author{
L. J. Atkinson ${ }^{1,2, *}$, J. G. Field ${ }^{1}$, L. Hutchings ${ }^{1,3}$ \\ ${ }^{1}$ Marine Research Institute, and ${ }^{2}$ Zoology Department, University of Cape Town, P Bag X3, Rondebosch, 7701, South Africa \\ ${ }^{3}$ Department of Environmental Affairs, P Bag X2, Rogge Bay 8012, South Africa
}

\begin{abstract}
This study is the first to examine the benthic impacts of the otter-trawl fishery on hake in the southern Benguela upwelling region. Infauna were sampled at 4 sites, from southern Namibia to Cape Town by means of 5 replicate grab samples at each of 2 trawling treatments (heavily and lightly trawled areas), paired at each site. The large invertebrate epifauna was also sampled at 2 of these sites using a fine-meshed otter trawl. Sites ranged in depth from 350 to $450 \mathrm{~m}$. Environmental attributes (sediment particle size, total organic carbon, depth, salinity, temperature and dissolved $\mathrm{O}_{2}$ concentration) were examined along with faunal assemblage composition. Vertical profiles of water mass characteristics showed little long-shore variation, apart from slightly lower $\mathrm{O}_{2}$ concentrations in the north. Difficulties of pseudo-replication in benthic impact studies are discussed, and methods for circumventing these suggested. There were significant differences in sediment characteristics among the 4 sites, but only 2 sites showed different sediment characteristics between trawling treatments. Studies of species richness, evenness and numbers of infaunal individuals showed little difference between trawling treatments at 3 sites and species diversity was similar between treatments at all 4 sites. Multivariate analyses show marked differences in both infaunal and epifaunal assemblages among the sites and between trawling treatments at all sites. The analyses suggest that differences in trawling intensity are at least partially responsible for significant variation in benthic assemblage composition between heavily and lightly trawled areas. These findings contrast to those in shallower waters in the northern hemisphere, where infauna are more sensitive to trawling than epifauna. This study shows that epifaunal abundances, number of species and species diversity decrease with increasing trawling intensity, and that there are also considerable changes in epifaunal assemblages in more heavily trawled sites.
\end{abstract}

KEY WORDS: Demersal trawl fishing · Fishing impacts · Infauna · Epifauna · Pseudo-replication · Benthic assemblages $\cdot$ Benthic biota $\cdot$ Benguela

Resale or republication not permitted without written consent of the publisher

\section{INTRODUCTION}

Mobile demersal fishing gears are deployed on every continental shelf in the world (Collie et al. 2000) with nearly 20 million $\mathrm{km}^{2}$ (75\% of the continental shelf) subjected to trawl and/or dredge activities (Kaiser et al. 2002). Such fishing activities have a profound effect on the ecosystem (Dayton et al. 1995, Jennings \& Kaiser 1998, Watling \& Norse 1998, Auster \& Langton 1999, Hall 1999, Kaiser \& de Groot 2000), and are one of the greatest sources of anthropogenic dis- turbance to marine benthic assemblages (Kaiser et al. $2000,2006)$. The challenge now lies in quantifying the extent of direct and indirect impacts at local, regional and ecosystem scales, and finding practical ways to mitigate the impacts.

Two approaches to quantifying trawl impacts are generally adopted. Chronic impact studies compare conditions between heavily fished, lightly fished and unfished areas, by assigning otherwise similar areas to treatments on the basis of historical estimates of trawling effort. This approach accurately represents 
trawling disturbance in terms of real effort and spatial dimensions (McConnaughey et al. 2000). Acute impact studies involve experimental fishing activity to contrast before and after effects between fished and unfished conditions. Such manipulative experimental approaches provide a more structured investigation but seldom accurately represent the effort and spatial scale of a commercial fishery. Both approaches are often used to investigate the effects of disturbance on invertebrate macrofauna, which plays important ecological roles in both structuring the habitat and as prey (Gray 1974).

Collie et al. (2000) and Kaiser et al. (2006) conducted global meta-analyses investigating the effects of different types of fishing impacts on benthic assemblages on various substrates, ranging from gravel to mud, and revealed the greatest impacts to be from scallop dredging activities in biogenic habitats. Kaiser et al. (2006) further identified soft-sediment habitats to be vulnerable to trawling with recovery times measured in years. These studies have provided useful information on the immediate effects, severity of impact and recovery times in a wide range of habitat types and environmental conditions. However, the fishing impact research assessed in these meta-analyses was typically of smallscale experimental studies at spatial scales measured in $\mathrm{km}^{2}$ (Collie et al. 2000, Kaiser et al. 2006). Furthermore, only one of the studies analysed (Engel \& Kvitek 1998) was conducted in an upwelling ecosystem (central California), whilst no studies analysed were conducted on sediments at outer shelf depths greater than $200 \mathrm{~m}$, i.e. conditions typical of the trawling grounds of the Benguela ecosystem.

Several studies conducted in the Irish and North Seas have examined the response of benthic biota to quantified gradients of fishing intensity at the scale of the fishery, thus assessing the effects of trawl disturbance under realistic conditions (Jennings et al. 2001, Hiddink et al. 2006, Queirós et al. 2006, Hinz et al. 2009). Results from these studies showed that impacts of chronic trawl disturbance are cumulative and can lead to profound changes in benthic assemblage composition, with both infauna and epifauna showing marked effects on sand and muddy substrates. Studies conducted at the scale of the fishery are essential to test predictions generated from smaller-scale experimental studies and provide applicable information to fishery managers and policy makers (Hinz et al. 2009).

Quantification of fishing impacts on the environment is frequently confounded by natural perturbations, a history of fishing activities and small-scale patchiness (Dayton et al. 1995, Jennings \& Kaiser 1998, Auster \& Langton 1999, Gordon et al. 2005). Interactions resulting from natural variability and trawling activities are illustrated in Fig. 1. Ideally, one would apportion these effects and compare fished areas to the same areas before fishing commenced. This is usually not possible when investigating large-scale ecosystems and one is confronted by issues relating to unreplicated sites and pseudo-replication, which Hurlbert (1984) defines as the use of inferential statistics to test for treatment effects where treatments are either not replicated or replicates are not statistically independent. Replication is often impossible or undesirable when investigating large-scale systems and when large effects of treatments are expected or when the cost of replication is great, experiments involving unreplicated treatment may be the best option (Hurlbert 1984, Oksanen 2001). Hurlbert (1984), however, cautions that conclusions derived from unreplicated treatments should not be extrapolated to broader application.

The most dramatic changes in the assemblage composition occur at the onset of fishing in a pristine area or when the fishing pressure increases dramatically from a very low level. Once fishing at a commercial scale has begun, the system enters a 'fished' state and any changes as a result of increased fishing intensity are often smaller and more difficult to detect (Jennings \& Kaiser 1998). Many of the world's demersal trawl grounds were transformed to a 'fished' state more than a century ago, well before the scientific value of pristine habitats was understood. The lack of suitable control sites is one of many reasons for establishing marine protected areas in ecosystems that are most heavily fished (Jennings \& Kaiser 1998).

The South African demersal otter-trawl fishery has existed for over 100 years and spans the southern Benguela upwelling region between depths of 200 to 800 m (Payne \& Punt 1995). It is South Africa's most valuable fishery and worth $\sim$ R2.5 billion or US\$ 365 million (FIH 2009). The Namibian demersal hake fishery started in the late 1950s (Boyer \& Hampton 2001) and is that country's largest, most lucrative fishery (Bianchi

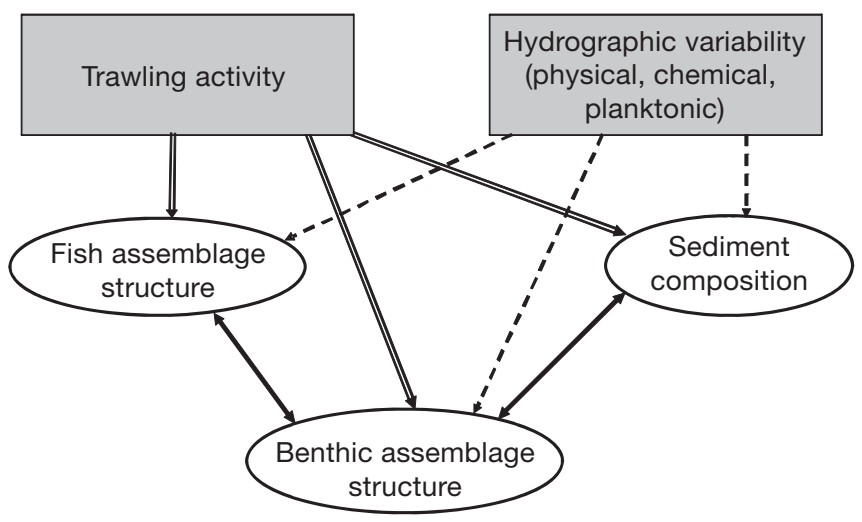

Fig. 1. Illustration of the complexity of interactions between trawling impacts and natural variability on benthic community structure. Solid lines $=$ direct effects; broken lines = natural variability; double arrows = interactions 
et al. 2001). Low oxygen water $\left(<2 \mathrm{ml} \mathrm{l}^{-1}\right)$, frequently associated with inshore areas $(<200 \mathrm{~m})$ in this upwelling region (Chapman \& Shannon 1985, Monteiro \& van der Plas 2006), is unlikely to directly impact biotic assemblages in deeper waters. However, changes in fish behaviour during such events (e.g. greater concentrations in deeper water and increased juvenile predation) and impacts on recruitment success (Hamukuaya et al. 1998) may indirectly influence deep-water benthic assemblages. Technological advances in fishing and vessel equipment since the 1950s have allowed the fishery to expand into deeper waters, down to $1000 \mathrm{~m}$ at times (Griffiths et al. 2004, Fairweather et al. 2006). The fishery operating in the southern Benguela region is comprised mostly of stern trawlers $\sim 50 \mathrm{~m}$ length, which use otter-trawl configurations with trawl doors 1.8 t each (Wilkinson \& Japp 2005). The physical impacts of demersal fisheries and their concomitant ecosystem effects have not previously been studied in an upwelling region or in southern Africa.

This study aims to quantify the effects of demersal trawling on benthic biota in the southern Benguela upwelling region. As with other similar studies (Engel \& Kvitek 1998, Thrush et al. 1998, Kaiser et al. 2000, Queirós et al. 2006, Hinz et al. 2009), there were no suitable, unfished control sites in the region. Comparisons of benthic biota between areas that are intensively fished with those of similar habitat type, but which are lightly fished, are the best alternative. Benthic invertebrate assemblages were sampled at 4 sites spanning the study region and compared between areas with different levels of trawling disturbance. This research aims to address the following questions:

(1) Does intense trawling result in significantly different abundance, biomass and/or diversity of benthic infaunal and/or epifaunal assemblages?

(2) To what extent can environmental effects be disentangled from anthropogenic effects in terms of impacts on benthic assemblages? (see Fig. 1)

(3) How do the impacts of trawling as detected by studies conducted in shallow areas at the scale of the fishery in Western Europe compare with those observed in deeper waters in upwelling regions?

\section{MATERIALS AND METHODS}

Study sites and sampling design. The spatial distribution of commercial fishing activity from 2003 to 2007 in South Africa was plotted using a geographic information system (GIS) with start to end points of actual trawl positions reported from vessel monitoring systems (Wilkinson \& Japp 2005), incorporating more recent unpublished data for this study. Namibian

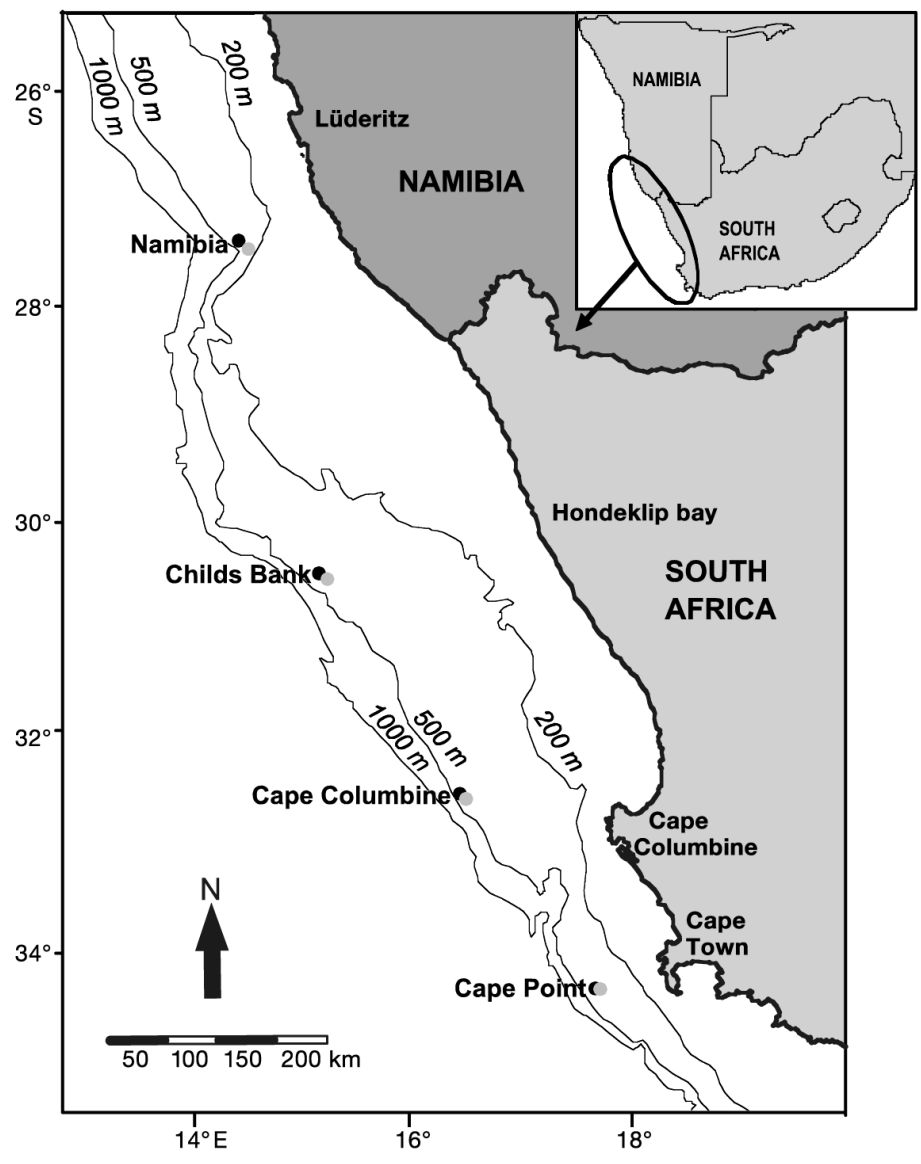

Fig. 2. Location of 4 selected sample sites. Black circles represent heavily trawled (HT) areas, grey circles represent lightly trawled (LT) areas

Catch Per Unit Effort (CPUE) data from 2004 to 2005 (MFMR 2005) were translated into hours fished. Based on this, 4 sites were identified (Fig. 2) as areas of intense commercial trawling (HT areas) with adjacent areas, in a similar habitat type, where trawling was considerably lighter (LT areas). Every effort was made to minimize differences in depth and sediment type between paired 'trawling treatment' areas. The 4 sites are named from north to south, Namibia, Childs Bank, Cape Columbine and Cape Point, respectively (Fig. 2) and ranged from 346 to $459 \mathrm{~m}$ depth (Table 1). The trawl intensity at each South African site, Childs Bank, Cape Columbine and Cape Point, was defined by calculating the number of trawl passes within a $0.5 \mathrm{n}$ mile radius of each site over a 5 year period (2003 to 2007) using unpublished commercial data obtained from the former Department of Environmental Affairs and Tourism, now Department of Agriculture, Forestry and Fisheries (DAFF). HT vs. LT areas sampled at the Namibian site were defined by the total number of hours fished in each area during 2004 and 2005 (MFMR 2005). To compare trawl intensity 
Table 1. Co-ordinates of benthic grabs and trawls, depths and trawl intensities at the sites sampled. Swept area gives an estimate of the proportion of the sampled area trawled per yr, based on the width of the net and number of trawl tracks. HT: heavily trawled; LT: lightly trawled

\begin{tabular}{|c|c|c|c|c|c|}
\hline & $\begin{array}{l}\text { Depth } \\
\text { (m) }\end{array}$ & $\begin{array}{l}\text { Trawl inten- } \\
\text { sity (no. } \mathrm{yr}^{-1} \text { ) }\end{array}$ & $\begin{array}{l}\text { Original } \\
\text { data }^{\mathrm{a}}\end{array}$ & $\begin{array}{l}\text { Proportion } \\
\text { swept area }\end{array}$ & $\begin{array}{l}\text { Depth } \\
(\mathrm{m})^{\mathrm{b}}\end{array}$ \\
\hline \multicolumn{6}{|c|}{ Namibia } \\
\hline HT & 405 & 1.8 to 2.7 & 18.3 to $27.7 \mathrm{~h}$ & 4.156 & 406 to 409 \\
\hline LT & 435 & 0.02 to 1.07 & 0.17 to $11 \mathrm{~h}$ & 1.011 & 446 to 453 \\
\hline \multicolumn{6}{|c|}{ Childs Bank } \\
\hline HT & 400 & 1.6 & 285 tracks & 2.939 & 399 to 400 \\
\hline $\mathrm{LT}$ & 350 & 0.17 & 30 tracks & 0.309 & 346 to 349 \\
\hline \multicolumn{6}{|c|}{ Cape Columbine } \\
\hline HT & 436 & 1.5 & 271 tracks & 2.795 & - \\
\hline LT & 412 & 0.6 & 112 tracks & 1.155 & - \\
\hline \multicolumn{6}{|c|}{ Cape Point } \\
\hline HT & 349 & 1.5 & 270 tracks & 2.784 & - \\
\hline LT & 348 & 1.04 & 187 tracks & 1.928 & - \\
\hline
\end{tabular}

mouth opening, $32 \mathrm{~mm}$ cod end mesh, lined with $25 \mathrm{~mm}$ mesh (defined as Gesund Super). All epibenthic invertebrate fauna retained by the net were sorted by taxon, identified, counted and weighed. All unknown specimens were preserved for further identification. Epifaunal abundance and biomass values were scaled to a uniform trawl duration of $30 \mathrm{~min}$. For the purposes of this study, infauna are defined as those invertebrates sampled by grab, whereas epifauna are defined as those sampled by trawl net. Due to the semi-quantitative nature of sampling epifauna by trawl net, the epifaunal abundance and biomass data were categorized on an approximately logscale for further analyses (Table 2).

Environmental variables. At each

among sites and with other studies, trawl tracks from South African sites and hours fished at the Namibian site were converted to estimated times trawled per year (shown in Table 1) using the equation (vessel speed in knots $) \times($ gear width in $\mathrm{m}) \times($ effort in $\mathrm{h}$ per yr) (see Hinz et al. 2009). The average width of the trawl net opening $(30 \mathrm{~m})$ and the average towing speed of offshore trawl vessels (3.5 knots) (Wilkinson \& Japp 2005) were also used to calculate the proportion of sampled area trawled per year (Table 1) at each site and area. These values provide comparable estimated fishing effort values based on the best currently available data.

Biological sampling. To sample the infauna, a $0.2 \mathrm{~m}^{2}$ van Veen grab was used to collect 5 replicate samples at each HT and LT area from all 4 sites from the RV 'Dr Fridtjof Nansen' in April 2007 and FRS 'Ellen Kuzwayo' in February 2008 (Cape Point, Table 1). Sediment volume for each grab was measured and $250 \mathrm{ml}$ sediment sub-samples collected for organic and sediment particle size analysis. The remaining sediment was washed over 2 stacked sieves with mesh sizes of 10 and $1 \mathrm{~mm}$ and with a $1 \mathrm{~mm}$ mesh covering the seawater hose, preventing large planktonic organisms from washing into the samples. All infauna $>1 \mathrm{~mm}$ in size retained by the sieves was placed into sample bottles and preserved in $96 \%$ ethanol, then replaced 24 to $48 \mathrm{~h}$ after initial preservation to ensure adequate preservation. Infauna was sorted and identified to the lowest possible taxonomic level, usually species. The abundance and biomass were recorded for each taxon.

Epifauna were sampled with 3 replicate trawls in HT and LT areas at the Namibian and Childs Bank sites during April 2007 (Fig. 2, Table 1). The trawl gear consisted of $47 \mathrm{~m}$ footrope with $12 \mathrm{~cm}$ roller disks, 18 to $22 \mathrm{~m}$ sampling site, water column profiles of depth, salinity, $\mathrm{O}_{2}$ and temperature were measured using a CTD meter.

Sediments were dry sieved to separate gravel ( $>2 \mathrm{~mm})$ and sand $(<2 \mathrm{~mm}$ and $>63 \mu \mathrm{m})$ while mud $(<63 \mu \mathrm{m})$ was wet sieved and quantified using a calculated pipetting factor according to standard conventions (Folk 1968). The mass of each component was converted into percentages and the gravel-sand-mud texture category of each replicate sample determined using Folk's classification triangle (Folk 1968).

The inorganic carbon component was removed from sediments by adding $50 \%$ hydrochloric acid. Sediment was dried and washed with $1 \mathrm{M}$ ammonium formate that removed any acid residue. The organic carbon contents were measured with a Thermo Flash 1112 elemental CHN analyzer.

Statistical and numerical analyses. Univariate analyses: Diversity indices (number of species, abundance, Pielou's species evenness, Shannon-Wiener diversity and average biomass per $0.2 \mathrm{~m}^{2}$ ) of infauna and epifauna (excluding biomass) were computed (Clarke \& Warwick 2001). The absolute values of epifaunal biomass were not appropriate for further uni-

Table 2. Categories allocated to abundance and biomass measures of epifauna collected from demersal trawls

\begin{tabular}{|lcc|}
\hline Category & Abundance (ind.) & Biomass (kg) \\
\hline 1 & $1-10$ & $0.001-0.010$ \\
2 & $11-100$ & $0.011-0.100$ \\
3 & $101-1000$ & $0.101-1.000$ \\
4 & $1001-10000$ & $1.001-10.000$ \\
5 & $10001-100000$ & $10.001-100.000$ \\
\hline
\end{tabular}


variate analysis as a result of prior log categorization. The response of univariate indices to trawling intensity per year were explored using least square regression analyses. Prior to analysis, abundance and biomass data were $\log _{10}$ transformed.

Environmental analyses: Proportions of sand and mud were strongly positively correlated (Pearson $\rho=$ 0.99), thus only one of these variables (\% sand) was used for further analysis. Gravel contributed very small proportions to the overall sediment composition $(<5 \%)$ and was excluded from further statistical analyses. Following arcsine transformation (Sokal \& Rohlf 1969, Zar 1999), replicate sand values and total organic carbon (TOC) were analysed separately. Statistical differences among sites and between treatments were analysed using ANOVA, with p-values determined by permutation rather than by reference to $F$ distribution tables, thus giving robustness to normality assumptions using permutational multivariate ANOVA (PERMANOVA) (Anderson et al. 2008). Factor trawling Treatment (fixed) was crossed with Sites (fixed factor) in a 2-way crossed ANOVA design.

Multivariate analyses: To test for differences in assemblage composition between trawl treatments, sample by species matrices were calculated for both abundance and biomass measures of infauna and categorized epifauna at all sites. The infaunal abundance and biomass matrices were 4 th root transformed (Field et al. 1982, Clarke \& Warwick 2001) while the epifauna data had effectively been transformed by log-scale categorization (Table 2). We compared samples on the basis of species abundances or biomasses using the Bray-Curtis measure of (dis)similarity on both infaunal and epifaunal data. These were summarized in cluster dendrograms and MDS plots. PERMANOVA (Anderson et al. 2008) was used to test for significant differences in assemblage structure among sites (Namibia, Childs Bank, Cape Columbine and Cape Point) and between trawling treatments HT vs. LT (Anderson et al. 2008). PERMANOVA was also used to test epifaunal abundance and biomass data between HT and LT areas at Namibia and Childs Bank. Treatment (fixed factor) was crossed with Site (fixed factor). PERMANOVA tests the dissimilarity values generated by the resemblance matrix on which permutations are based, generating a test statistic value of pseudo- $F$ and pseudo- $t$ for pair-wise tests (Anderson et al. 2008). However, these tests were compromised by pseudoreplication and the probabilities calculated are too low. The tests were therefore repeated using the interaction term as the denominator in the F-ratio, giving an ultraconservative probability value. The true probability lies somewhere between the 2 calculated values, depending upon the degree of pseudo-replication (K. R. Clarke pers. comm.). To assess which species con- tribute most to differences between groups, SIMPER analyses were conducted (Clarke 1993).

The relationships between biotic (abundance and biomass) assemblage data and all measured environmental variables were investigated using a Distance Based Linear Model (DISTLM) (Anderson et al. 2008). Trawl intensity was used to quantify fishing pressure in the DISTLM analysis as a continuous variable (times trawled per yr). The contribution of environmental variation and fishing pressure in influencing the biotic data distribution was simultaneously assessed. DISTLM partitions the variation in data distribution according to a multiple regression model (based on predictor variables), as selected by the user, e.g. forward, stepwise, best fit. The 'forward' procedure and Adjusted $\mathrm{R}^{2}$ criteria options (Anderson et al. 2008) were used in this study. The environmental variables selected for the model were Sand, TOC (arcsine transformed), Depth and Times trawled per year. All multivariate and diversity analyses were performed using PRIMER v.6 and its add-on package PERMANOVA+ (Clarke \& Warwick 2001, Clarke \& Gorley 2006, Anderson et al. 2008).

\section{RESULTS}

\section{Environmental variables}

Table 3 summarises the results of sediment and water column characteristics measured at the areas sampled. There is little variation in water temperatures or salinities at the 8 sites. The entire sampling region was thus uniform with respect to water mass characteristics during the sampling period, although it is noted that the Namibian areas had lower near-bottom $\mathrm{O}_{2}$ levels than the other 3 sites. Sites sampled in this study were deeper than the coastal hypoxic region where the biota are likely to be influenced seasonally by reduced $\mathrm{O}_{2}$ levels (Decker 1970, Monteiro \& van der Plas 2006),

The sediments were classified according to the Folk Classification triangle (Folk 1968). A conventional main effects PERMANOVA test shows significant differences in Sediments among Sites, between Treatments and the interaction between Sites and Treatments (Table 4). However, these tests are compromised by pseudo-replication and non-independence; thus ultraconservative tests are also presented (right hand columns, Table 4) using the interaction term as the denominator in calculating the F-value (K. R. Clarke pers. comm.). Here only TOC was found to differ significantly among sites, mainly due to the high values at Childs Bank (see Table 3). The true significance levels lie somewhere between the conventional and ultraconservative tests. 
Table 3. Sediment and water column characteristics measured at each heavily trawled (HT) and lightly trawled (LT) sample area. Sand and total organic carbon (TOC) data are mean $\pm \mathrm{SE}(\mathrm{n}=5)$. Temperature was 7 to $8^{\circ} \mathrm{C}$ and salinity was 34.6 to 34.8 at all sites

\begin{tabular}{|lcccc|}
\hline & Sediment & $\begin{array}{c}\text { Sand } \\
(\%)\end{array}$ & $\begin{array}{c}\text { TOC } \\
(\%)\end{array}$ & $\begin{array}{c}\text { Oxygen } \\
\left(\mathrm{ml} \mathrm{l}^{-1}\right)\end{array}$ \\
\hline Namibia & Muddy sand & $83.16 \pm 0.45$ & $0.64 \pm 0.08$ & 2 \\
HT & $\begin{array}{c}\text { Sand-muddy sand } \\
\text { LT }\end{array}$ & $89.18 \pm 1.37$ & $1.48 \pm 0.24$ & 2 \\
Childs Bank & Muddy sand & $77.04 \pm 2.23$ & $14.23 \pm 0.41$ & 4 \\
HT & Muddy sand & $72.61 \pm 0.68$ & $11.37 \pm 0.35$ & 4 \\
LT & & & \\
Cape Columbine & & & \\
HT & Muddy sand-sandy mud & $52.56 \pm 2.56$ & $2.85 \pm 0.24$ & 4 \\
LT & Sandy mud & $21.22 \pm 0.79$ & $5.55 \pm 0.48$ & 4 \\
Cape Point & & & & \\
HT & Muddy sand & $84.35 \pm 1.26$ & $0.89 \pm 0.06$ & 4 \\
LT & Muddy sand & $78.04 \pm 3.06$ & $1.25 \pm 0.19$ & 4 \\
\hline
\end{tabular}

The species richness and diversity follow identical trends, although these are not significant. Owing to the semiquantitative logarithmic categorization of the epifauna data (Table 2), the diversity and evenness values in Fig. 3 should not be compared with other studies.

\section{Benthic infauna}

A species accumulation curve (not shown) of all 40 infaunal grab samples approaches an asymptote, suggesting that the 256 species obtained approximate those occurring in this Benguela ecosystem habitat. Fig. 4 shows a MDS plot based on infaunal abundance data from all sites, depicting 4 main site

\section{Univariate measures of biotic diversity}

Fig. 3 depicts the trends and least-square regression analysis results in various measures of diversity plotted against trawling intensity (times trawled per yr) measured at all 4 sites and both HT and LT areas. For the infauna, there is little trend and generally a wide scatter for evenness, biomass and species diversity with no significant regression analyses. The fits are slightly better for overall abundance and species richness (number of species), but the regression analyses remain non-significant. The results are rather different for the epifauna, although the data are only from 2 sites. The fits for species richness, overall abundance, and diversity are better $\left(\mathrm{R}^{2}>87 \%\right)$, with negative slopes for all 4 measures, suggesting negative impacts of trawling on the epifauna. Only the abundance measures show a significant decline between HT and LT areas $(F=19.13, \mathrm{df}=1,2, \mathrm{p}=0.048)$. groups, and also shows at Namibia and Childs Bank clear separation of HT and LT areas. At the other 2 sites, HT and LT areas are not as well separated. Analysis of biomass data from all sites showed a similar MDS grouping pattern (not shown). This suggests that the biogeographic variation with latitude accounts for greater variation than between heavily and lightly trawled areas at each site.

Main effects PERMANOVA of the same abundance data shows significant differences among Sites, Treatments and the interaction between Sites and Treatments (Table 5). However, just as for the environmental data, these results are compromised by pseudoreplication and the significance levels are exaggerated. Again, very conservative pseudo- $F$ tests, using the interaction mean square as a denominator, are presented in the right hand columns, but these are not significant for Site or Treatment and add little information to the analysis.

Table 4. Test statistics for main effects PERMANOVA of percentage of sand and total organic carbon (TOC, arcsine transformed) among 4 sites with heavily trawled and lightly trawled areas. The number of unique permutations possible exceeded 9000 in all cases. Significant values at $\mathrm{p}<0.05$ are indicated in bold. Conservative $F$-ratio has interaction mean squares value as denominator

\begin{tabular}{|c|c|c|c|c|c|c|c|}
\hline & df & SS & MS & $\begin{array}{c}\text { Pseudo- } F \\
\text { (conventional) }\end{array}$ & $\mathrm{p}$ & $\begin{array}{c}\text { Pseudo- } F \\
\text { (conservative) }\end{array}$ & $\mathrm{p}$ \\
\hline \multicolumn{8}{|l|}{ Sand } \\
\hline Site & 3 & 32.103 & 10.701 & 264.45 & 0.0001 & 7.5 & $>0.05$ \\
\hline Treatment & 1 & 1.324 & 1.324 & 32.72 & 0.0001 & 0.93 & $>0.05$ \\
\hline Site $\times$ Treatment & 3 & 4.278 & 1.426 & 35.239 & 0.0001 & - & - \\
\hline \multicolumn{8}{|l|}{ TOC } \\
\hline Site & 3 & 36.410 & 12.137 & 444.81 & 0.0001 & 21.2 & $<0.05$ \\
\hline Treatment & 1 & $3.879 \times 10^{-4}$ & $3.879 \times 10^{-4}$ & $1.42 \times 10^{-2}$ & 0.9091 & $6.78 \times 10^{-4}$ & $>0.05$ \\
\hline Site $\times$ Treatment & 3 & 1.717 & 0.572 & 20.97 & 0.0001 & - & - \\
\hline
\end{tabular}



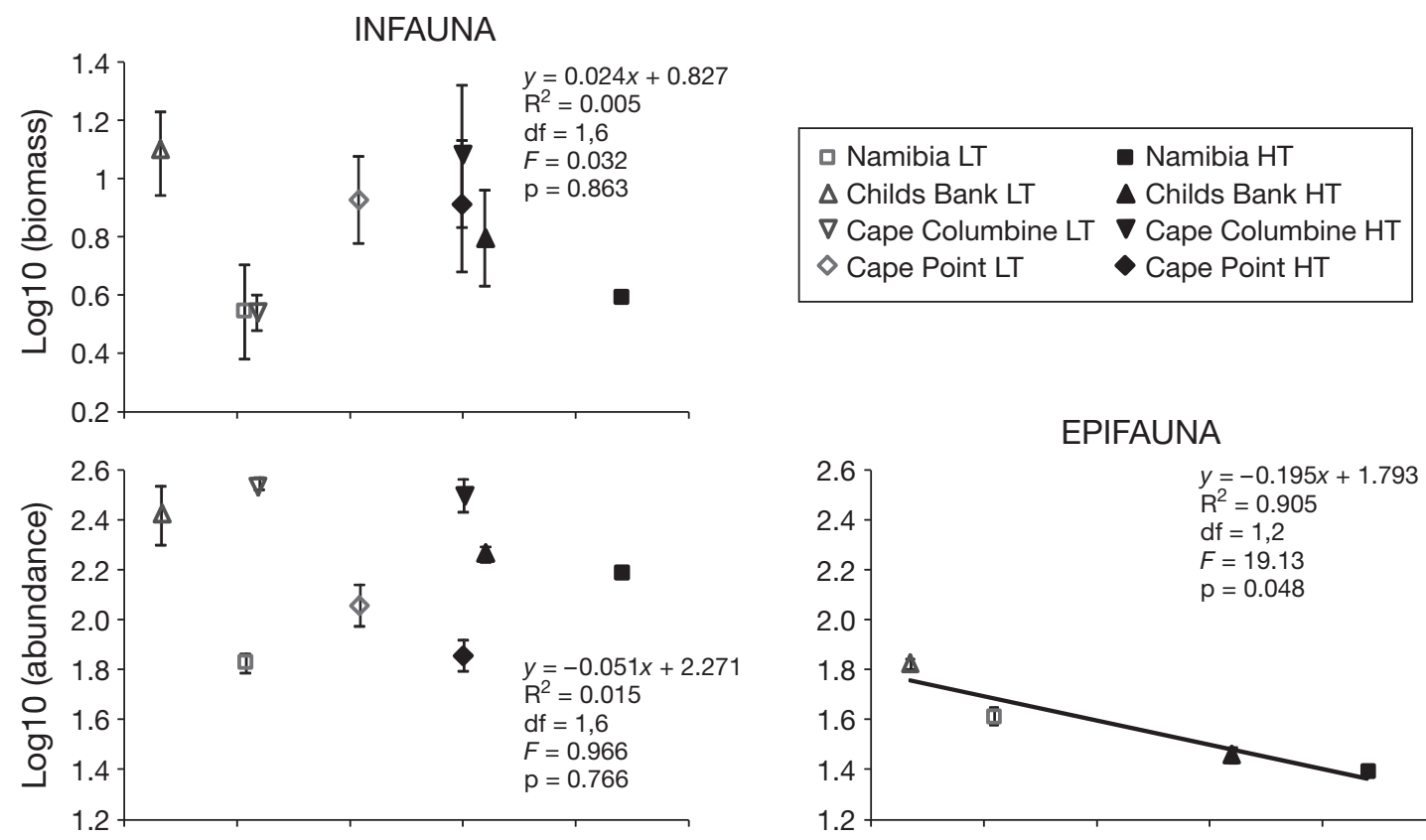

\section{EPIFAUNA}
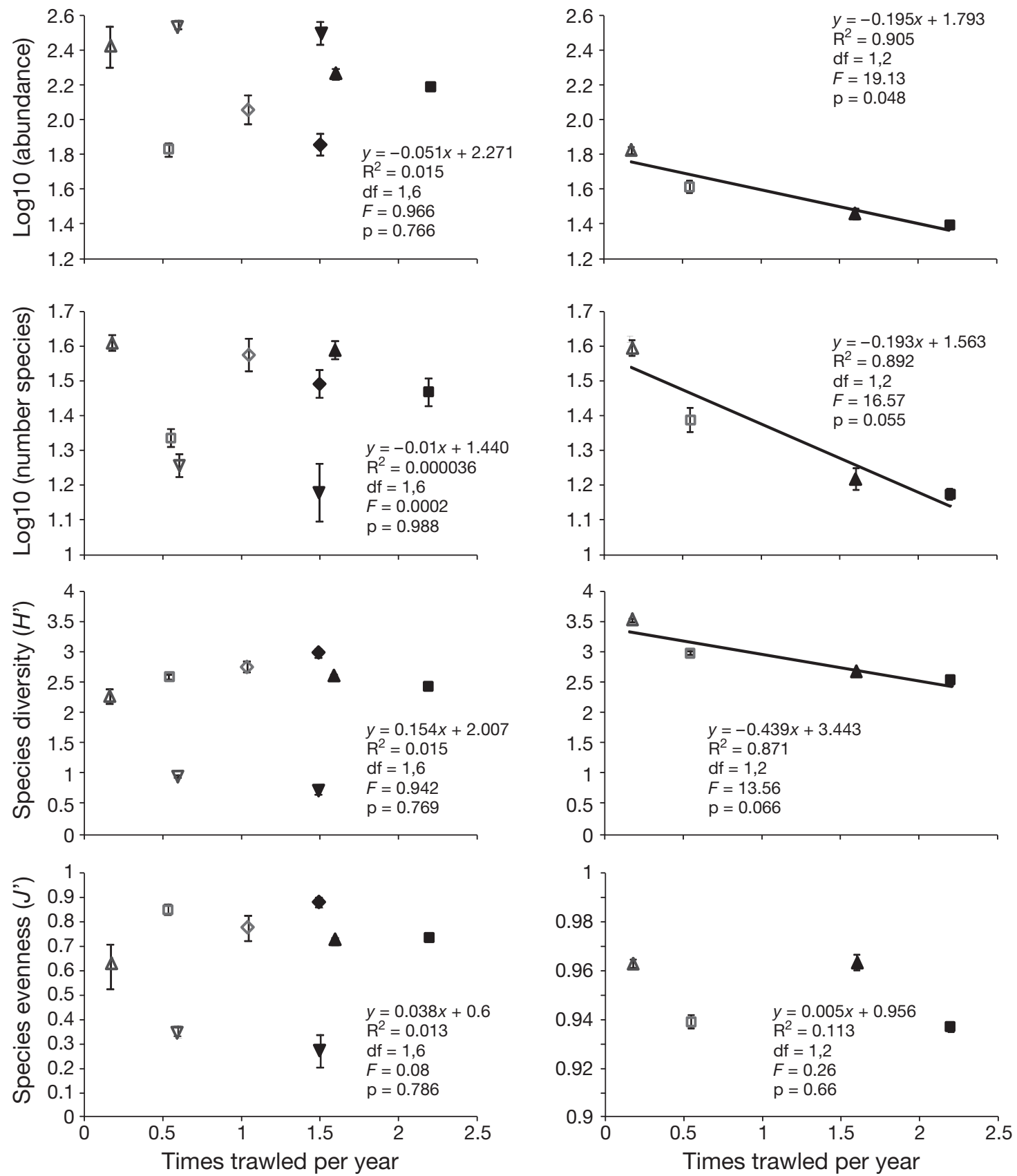

Fig. 3. Infaunal and epifaunal diversity indices with least square regression analysis results included. Regression lines included only if $\mathrm{R}^{2}>0.85$. HT: heavily trawled; LT: lightly trawled 
Infaunal indicator species

The main species responsible for the Bray-Curtis MDS clusters are revealed by a SIMPER analysis (Clarke 1993) comparing trawling treatments (Fig. 5). A few species showed consistent trends among sites where the echinoderm Ophiura sp. are more abundant at HT areas and the polychaete Chloeia inermis had higher biomass at LT areas, while others, e.g. the echinoderms Amphiura sp. and Brissopsis lyrifera capensis, showed irregular occurrence among sites and trawling treatments. Several species were unique to specific sites and occurred either exclusively, or in greater biomass, at LT areas. These include the tanaid crustaceans Apseudes cooperi at Namibia and Tanais philetaerus at Cape Columbine, an unidentified ascidian, sipunculid Phascolosoma sp. and chiton Leptochiton sykesi at Cape Point.

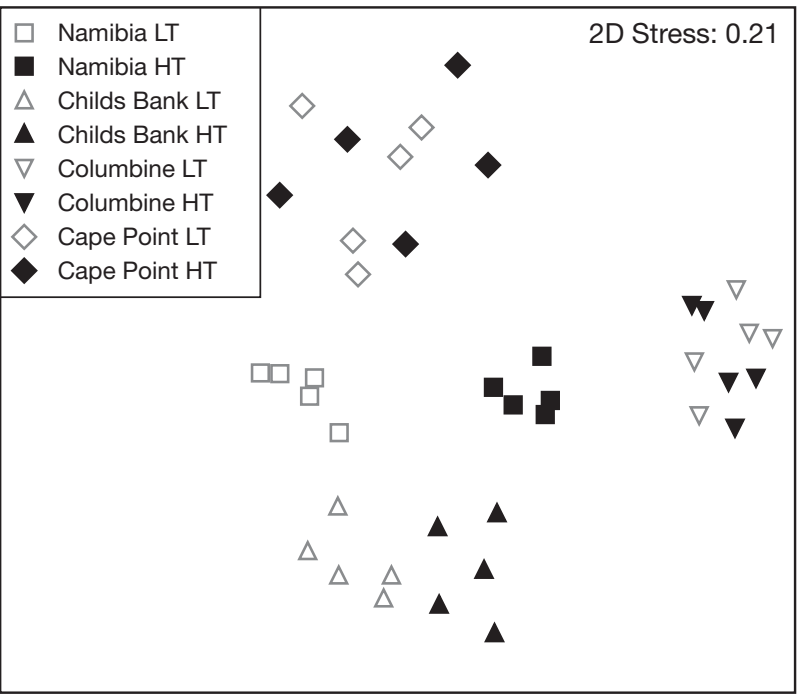

Fig. 4. Infaunal abundance: multi-dimensional scaling plot of all study sites and treatments after 4th root transformation, based on Bray-Curtis similarity. HT: heavily trawled; LT: lightly trawled
Relation of infauna to environment and trawling treatment

The relationship of infaunal assemblage composition (based on abundance data) to both natural and trawling influences was investigated using a linear modelling approach, DISTLM. The results are given in Table 6 . The pseudo- $F$ tests are again potentially compromised by pseudo-replication, but it can be seen that all 4 variables contribute considerably to the variation observed (marginal tests). To disentangle trawling effects from natural variability, sequential tests were also applied that showed the cumulative effects of each variable once the previous variable(s) had been accounted for. The sequence specified started with natural variables (sediment properties) with trawling intensity being fitted last. Sand and TOC, together with depth, account for $37 \%$ of infaunal variability, whilst trawling intensity accounts for only $5.3 \%$ direct effect on infauna. These results do not take into account the possibility that trawling may influence sediment composition made up of sand and TOC and thereby indirectly influence the assemblage composition. Similar results were obtained using biomass data but are not presented here.

\section{Epifauna}

A total of 81 epifaunal species was sampled at the Childs Bank and Namibian sites. Fig. 6 shows 4 groups of 3 samples each, with the 2 sites well separated, and Namibian trawl treatments closer to each other than the Child's Bank treatments. The low stress value (0.05) indicates the validity of the 2-D presentation of this small data set.

Epifaunal biomass SIMPER analyses (Fig. 7) reveal that several species of urchins such as the Spatangus capensis, Echinus gilchristi and Brissopsis lyrifera capensis and the crab Exodromidia spinosa occur at LT areas, while other species such as the bristle worm Euphrosine sp. show great variability between trawling treatments at

Table 5. Infauna: test statistics for main effects PERMANOVA of infaunal abundance and biomass. The number of unique permutations possible exceeded 9000 in all cases. Conservative F-ratio has interaction mean squares value as denominator

\begin{tabular}{|c|c|c|c|c|c|c|c|}
\hline & df & SS & MS & $\begin{array}{c}\text { Pseudo- } F \\
\text { (conventional) }\end{array}$ & $\mathrm{p}$ & $\begin{array}{c}\text { Pseudo-F } \\
\text { (conservative) }\end{array}$ & $\mathrm{p}$ \\
\hline \multicolumn{8}{|l|}{ Abundance } \\
\hline Site & 3 & 44125 & 14708 & 10.72 & 0.0001 & 3.3 & $>0.05$ \\
\hline Treatment & 1 & 4071.5 & 4071.5 & 2.97 & 0.0001 & 0.93 & $>0.05$ \\
\hline Site $\times$ Treatment & 3 & 13183 & 4394.4 & 3.20 & 0.0001 & - & - \\
\hline \multicolumn{8}{|l|}{ Biomass } \\
\hline Site & 3 & 44503 & 14834 & 9.43 & 0.0001 & 3.3 & $>0.05$ \\
\hline Treatment & 1 & 4474.8 & 4474.8 & 2.85 & 0.0001 & 2.93 & $>0.05$ \\
\hline Site $\times$ Treatment & 3 & 15164 & 5054.6 & 3.21 & 0.0001 & - & - \\
\hline
\end{tabular}




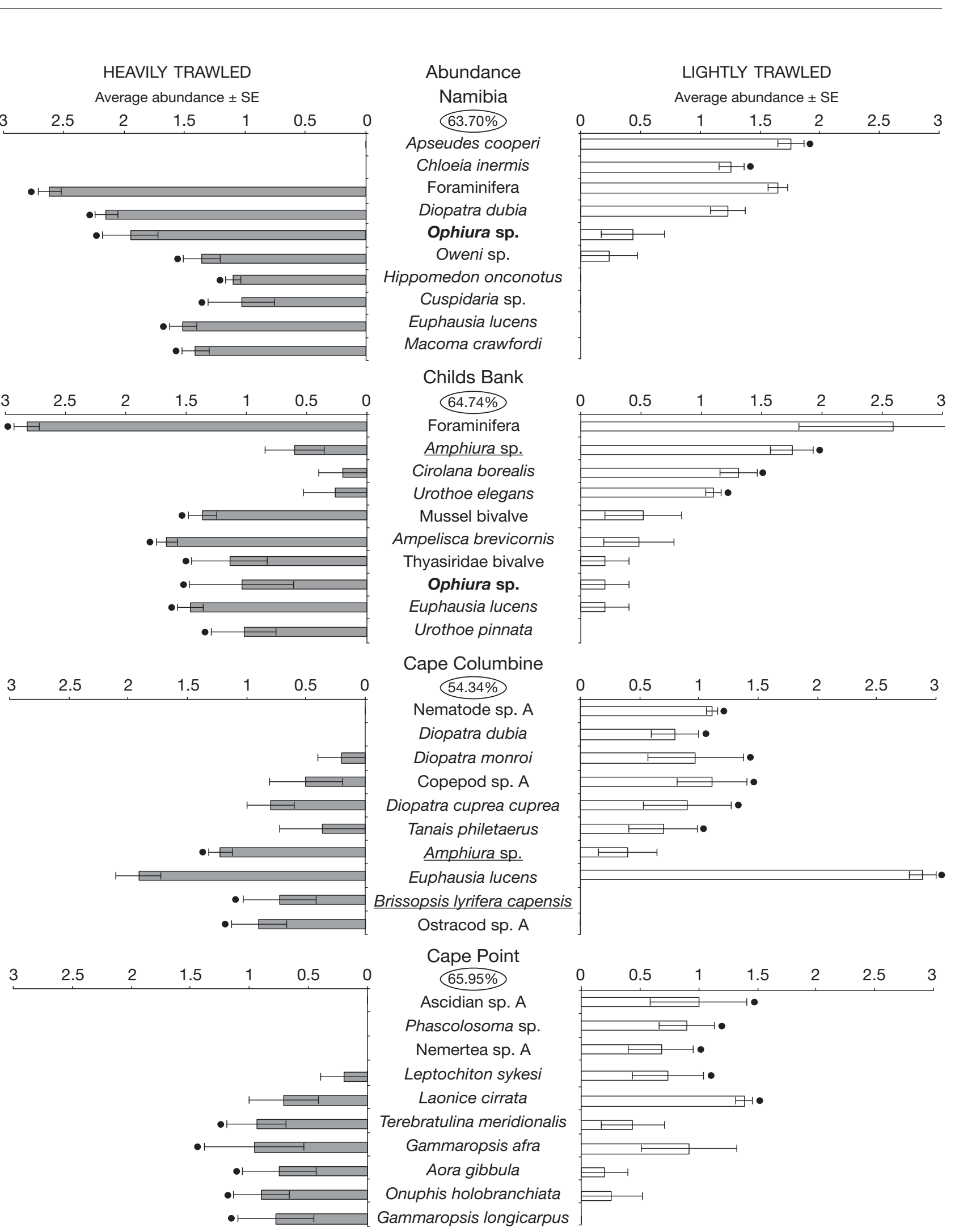

Fig 5. Infaunal SIMPER analysis of abundance data (top 9 species contributing to differences) between lightly and heavily trawled areas at each site $( \pm$ SE) after 4 th root transformation and Bray-Curtis dissimilarity. Species in bold show consistent trends between sites. Species underlined show opposite trends between sites. Percentage dissimilarity between treatments at each site is indicated in ellipse. A black circle indicates the area of greater abundance per species 
Table 6. Test statistics for Distance-based Linear Model (DISTLM) analyses marginal and sequential tests based on 'Forward' procedure and Adjusted $\mathrm{R}^{2}$ criteria of infaunal abundance at the 4 sites sampled. Marginal tests show how much variation each variable explains when considered alone, ignoring other variables. Sequential tests explain the cumulative variation attributed to each variable fitted to the model in the order specified, taking previous variables into account

\begin{tabular}{|c|c|c|c|c|c|c|c|}
\hline Variable & Adjusted $\mathrm{R}^{2}$ & SS (trace) & Pseudo- $F$ & $\mathrm{p}$ & Proportion & Cumulative & Residual df \\
\hline \multicolumn{8}{|l|}{ Marginal tests } \\
\hline Sand & - & 16399 & 7.0106 & 0.0001 & 0.15575 & - & - \\
\hline TOC & - & 11355 & 4.5935 & 0.0001 & 0.10785 & - & - \\
\hline Depth & - & 13887 & 5.7737 & 0.0001 & 0.1319 & - & - \\
\hline Times trawled & - & 4617.9 & 1.7431 & 0.459 & 0.04386 & - & - \\
\hline \multicolumn{8}{|l|}{ Sequential tests } \\
\hline+ Sand & 0.13354 & 16399 & 7.0106 & 0.0001 & 0.15575 & 0.15575 & 38 \\
\hline$+\mathrm{TOC}$ & 0.2347 & 12444 & 6.023 & 0.0001 & 0.11819 & 0.27395 & 37 \\
\hline +Depth & 0.32098 & 10452 & 5.7015 & 0.0001 & 0.09926 & 0.37321 & 36 \\
\hline +Times trawled & 0.36121 & 5634.1 & 3.267 & 0.0001 & 0.05351 & 0.42672 & 35 \\
\hline
\end{tabular}

the 2 sites. The burrowing anemone Actinauge richardii consistently occurs in greater abundance and biomass in heavily trawled areas at both sites.

\section{DISCUSSION}

\section{Sampling design}

In studying the effects of trawling, it is difficult in practice to find areas of habitat suitable for trawling that are not trawled at all. The best alternative under these circumstances is to study areas that are heavily trawled for comparison with lightly trawled areas of comparable habitat (McConnaughey et al. 2000). We approached this study using a 2-way crossed design to separate variation due to trawling (treatment) and

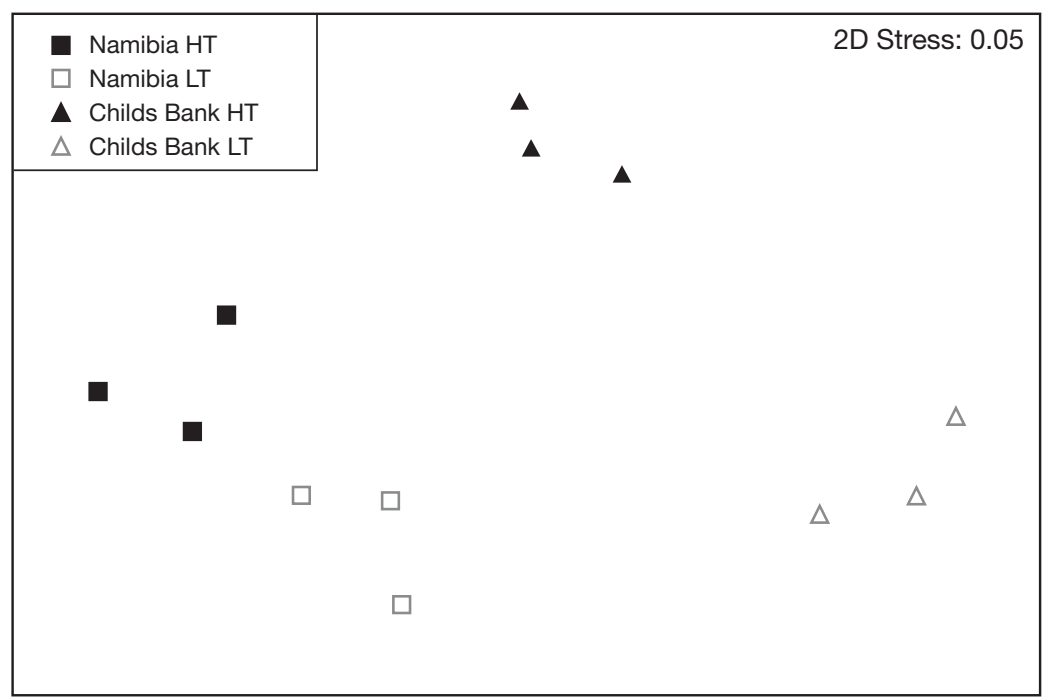

Fig. 6. Epifaunal abundance: multi-dimensional scaling plot of categorized data at Namibia and Childs Bank with paired heavily trawled (HT) and lightly trawled (LT) areas to natural environmental variability using both conventional ANOVA and multivariate PERMANOVA in which the $F$-ratio is calculated using the remainder (error) MS term as the denominator. In doing this it is almost impossible to avoid issues of pseudoreplication. The conventional $F$-ratios calculated give unrealistically low probabilities under the null hypothesis of no effect. The large values of the interaction MS term evident in this study (Tables 4 \& 5) suggest that pseudo-replication may indeed be a problem (K. R. Clarke pers. comm.). To account for this we recalculated the $F$-ratios using the interaction term in the denominator. This gives an ultra-conservative result, which if significant, indicates that the effect is certainly real. In the present study we found that the sedimentary organic carbon differed significantly among the 4 sites (Table 4), but there were no other significant effects on the sediments (Table 4) or infaunal assemblages (Table 5) among sites or between trawling treatments based on the ultra-conservative tests. To mitigate potential pseudo-replication problems, future studies of this nature should do one of the following:

(1) Sample more areas within each site, so that there are multiple areas which have been lightly trawled interspersed with multiple areas that have been more heavily impacted, the likelihood being that this sampling would be at the expense of reducing the number of wide-scale locations visited. The possibility then exists of differentiating natural variability from trawling impacts, at the geographic scale of that site.

(2) Sample more wide-scale sites whilst retaining the pairwise matching of a heavily and lightly trawled area at 
HEAVILY TRAWLED

Average abundance \pm SE

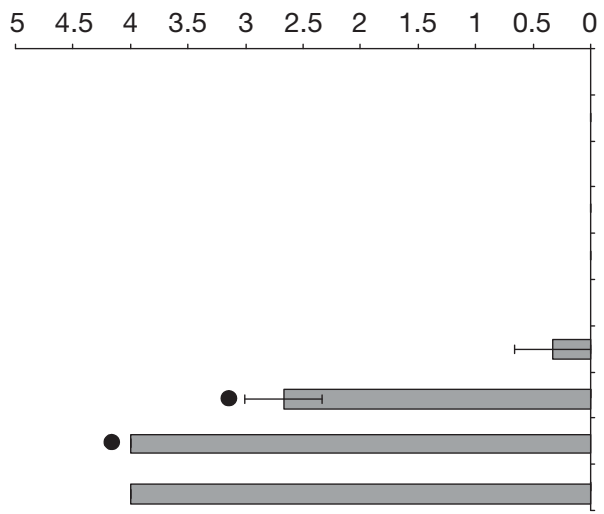

$\begin{array}{lllllllllll}5 & 4.5 & 4 & 3.5 & 3 & 2.5 & 2 & 1.5 & 1 & 0.5 & 0\end{array}$
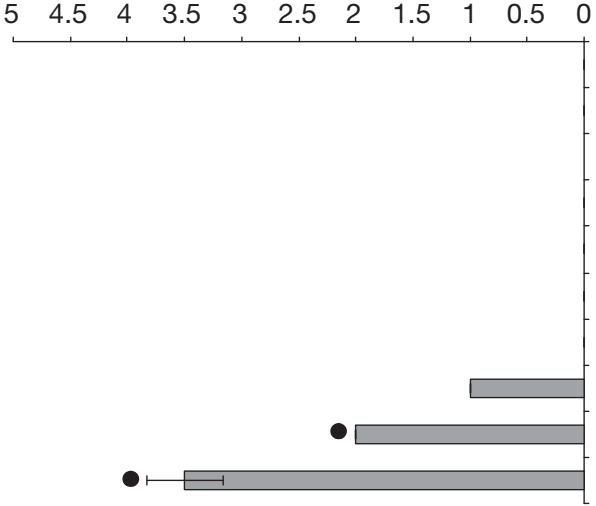

Categorized abundance

Namibia

$50.81 \%$

Euphrosine sp.

Parapagurus dimorphus

Plesionika martia

Merhippolyte agulhasensis

Spatangus capensis

Echinus gilchristi

Stereomastis sp.

Actinauge richardii

Parapagurus pilosimanus

Mixed prawns

Childs Bank

$$
\text { 64.04\% }
$$

Rosella antarctica

Acbaria rubra

Opistobranch sp. B

Cold water coral

Spatangus capensis

Exodromidia spinosa

Parapagurus pilosimanus

Hermit crabs

Actinauge richardii

Euphrosine sp.
LIGHTLY TRAWLED

Average abundance \pm SE

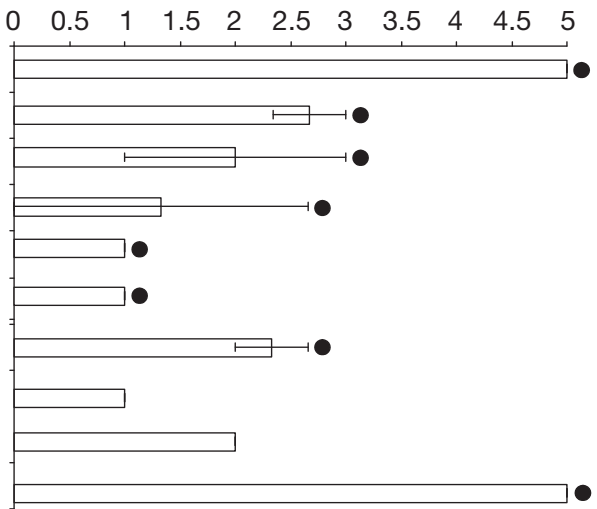

$\begin{array}{llllllllllll}0 & 0.5 & 1 & 1.5 & 2 & 2.5 & 3 & 3.5 & 4 & 4.5 & 5\end{array}$

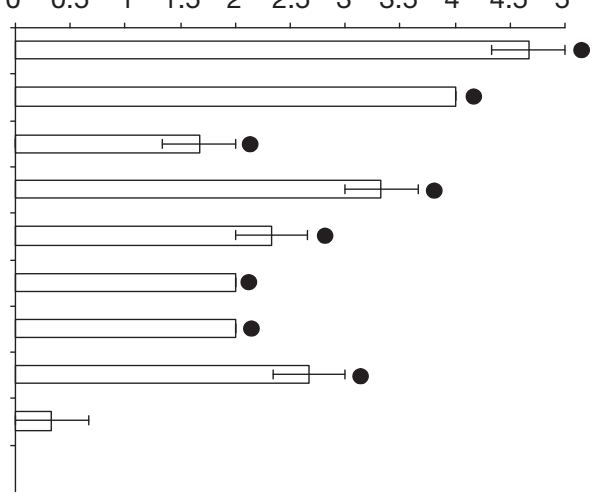

Fig. 7. Epifaunal SIMPER analysis of categorized abundance data (top 10 species contributing to differences) between lightly and heavily trawled areas at each site $( \pm \mathrm{SE})$ with Bray-Curtis dissimilarity. Species in bold show consistent trends between sites. Species underlined show opposite trends between sites. Percentage dissimilarity between treatments at each site is indicated in ellipse. A black circle indicates the area of greater abundance per species

each site. This would allow inference about differences in trawling impact at much wider spatial scales to be drawn. No information is then available for a particular site about whether observed differences between heavily and lightly trawled areas is really due to trawling levels or other environmental conditions, but such findings may result from the set of wide-scale sites as a whole. In the ANOVA terminology of the above results, the number of degrees of freedom for the interaction mean square may be sufficiently large so that a consistent trawling effect at all sites manifests itself as a significant main effect of trawling in relation to the interaction mean square. The appropriate model here is that of a 2-way crossed design in which the trawling effect is fixed but the site-to-site variation is a random effect.

Which of these 2 strategies is preferable will therefore depend on a host of factors, including the aims of the study. It is, however, important to note that there can only be limited gains from increasing the number of replicate grabs or trawls in an area, by comparison with an increase in effort at a higher level of the design. More incisive analyses would come from using BACI designs, which allow comparisons of before and after implementing no-fishing control measures in the same areas.

\section{Diversity indices versus multivariate methods}

This study found no relationship between trawling intensity and the infaunal univariate measures of total abundance, biomass, species richness, diversity and evenness over all 4 sites. This contrasts with results from studies conducted in the Irish and North Seas (Jennings et al. 2001, Hiddink et al. 2006, Queirós et al. 2006, Hinz et al. 2009) where significant effects of trawling intensity were found in univariate measures of infaunal abundance, biomass, species richness and/or productivity in considerably shallower $(<75 \mathrm{~m})$ 
mud or sandy sediment environments. Furthermore maximum trawling intensities investigated in the Irish and North Sea studies ranged from 3.5 to 18.2 times per yr compared to only 2.3 times per yr in the present study. Epifauna sampled in the Benguela region showed a significant decline in total abundance with increasing trawling intensity, while species richness and diversity also declined, but not significantly (Fig. 3). This contrasts in some respects with the results of Hiddink et al. (2006) and Hinz et al. (2009), who found that univariate measures of epifaunal biomass, production, abundance and/or species richness differed significantly with trawling intensity, but that overall infauna were more sensitive than epifauna. A study conducted by Engel \& Kvitek (1998) in the upwelling, deeper $>180 \mathrm{~m}$, region of central California, however, report greater changes in epifaunal species than infauna when comparing heavily and lightly fished areas, findings similar to the present study.

Multivariate results are slightly more conclusive, in that the multi-dimensional scaling graphs depict differences among the sites for both infauna (Fig. 4) and epifauna (Fig. 6), with distinct differences between trawling effects for 2 of the 4 infaunal sites (Namibia and Childs Bank) and both epifaunal sites (also Namibia and Childs Bank). These results are similar to those of Hinz et al. (2009). Our attempt to confirm these graphical multivariate results statistically was confounded by pseudo-replication. Multivariate graphical results have however proved to be robust and generally give clearer results in this situation than the univariate diversity indices. Similar findings are reported by Kaiser et al. (1998) and Thrush et al. (1998) from studies conducted to detect changes due to trawling. Multivariate analyses are considered to incorporate a greater amount of assemblage information and have been suggested to be more sensitive at detecting changes in assemblages than univariate measures (Gray et al. 1990, Warwick \& Clarke 1991).

\section{Separating trawling from environmental effects}

Multivariate graphical results show larger inter-site differences than within-site trawling treatment differences for infauna (Fig. 4) and marginally for epifauna (Fig. 6). However, these results are complicated by the large sedimentary differences between areas and sites. This is particularly so at Cape Columbine where the percentage of sand ranged from $52 \%$ at the HT area to $21 \%$ at the LT area, compared to 72 to $89 \%$ sand at all other sites and areas (Table 3). Was the area lightly trawled because the fish assemblage was different due to the different sediment, or was the difference in sediment due to less trawling? Evidence from the other 3 sites suggests that trawling may have little effect on the sediments. Similarly, percentage of TOC was significantly higher at Childs Bank than at all other sites (Table 4). With such large variability among sites in the benthic environment, even at similar depths, it is very difficult to show significant differences between trawling treatments and to distinguish trawling effects from environmental ones. Thus the conservative form of the PERMANOVA showed no significant differences among sites or treatments (Table 5), although the conventional analyses were all significant for both infaunal abundance and biomass data. The DISTLM marginal analyses were all significant for environmental and treatment variables in explaining infaunal assemblage variation (Table 6) but the various 'explanatory' variables are not independent of each other and need to be considered in combination. Sequential tests that eliminate the contributions of previous variables, and specify sedimentary variables fitted first, show that environmental variables contribute a cumulative $37 \%$ to variability with trawling contributing a further $5.3 \%$ to the overall assemblage variation, with the remaining $57.4 \%$ unexplained (Table 6 ). The relative percentage variation accounted for when fitting environmental variables first, indicates the potentially small size of any direct trawling effects in relation to that of the differing environmental conditions. In view of the complex processes involved in influencing benthic assemblage structure (see Fig. 1), and taking into account the difficulties of replicate sampling and obtaining a strong gradient of trawling intensities, it was impossible to obtain statistically rigorous results to separate trawling effects from environmental ones in this study. A similar difficulty was reported by Queirós et al. (2006), where the impact of trawling could not be disentangled from that of sediment composition.

In comparing infaunal and epifaunal species indicative of trawling effects in studies in the Benguela and California upwelling regions and Irish and North Seas, it is evident that different animal groups are likely to serve as potential indicators of the effects of trawling (Table 7). In the Benguela and Californian infaunal analysis, an ophiuroid brittle star increased with heavier trawling, while the polychaete Chloeia sp. decreased in the Benguela but increased in California. In the Irish Sea Prionospio spp. polychaetes increased, while Phoronis sp., molluscs and nemertea decreased. In the case of the Benguela epifauna, a burrowing anemone Actinauge richardii increased while the echinoid urchins Spatangus, Echinus and Brissopsis decreased. In California, no epifaunal species were reported to increase with heavier trawling while species of sea pen, sea star, anemone and sea slug all decreased. There were no significant epifaunal species 
changes in the Irish Sea study (Hinz et al. 2009). Thus it appears that different groups and components of the benthos are affected differently in different environments, bearing out the general conclusions of Kaiser et al. (2006), who studied different sediment types and different types of fishing.

\section{Comparison of shallow versus deep trawling}

Assessing trawl impacts at 4 sites spread over $800 \mathrm{~km}$ at about $400 \mathrm{~m}$ depth on the outer continental shelf of the Benguela upwelling ecosystem show some similarities to a study conducted in the central California upwelling region (Engel \& Kvitek 1998) and some differences from studies conducted in sheltered, shallower waters in western Europe (Jennings et al. 2001, Hiddink et al. 2006, Queirós et al. 2006, Hinz et al. 2009). Despite the greater depth, the sediments of the Benguela outer shelf otter-trawl grounds are generally classified as muddy sand (Table 3), being coarser than the muds of the shallow (26 to $75 \mathrm{~m}$ depth) North and Irish Seas environments. The intensity of heavy trawling was much greater in western Europe (up to 18.2 times per yr) and California (4 times per yr) compared to only 2.3 times per yr in the Benguela system. Where multivariate analyses were used (Hinz et al. 2009, present study), graphical separation of infaunal and epifaunal assemblages between heavily and lightly trawled areas was evident, with slightly clearer separation for epifauna. Results from western European studies showed greater change in infaunal than epifaunal univariate indices while results from the Benguela upwelling ecosystem showed greater epifaunal change (Fig. 3), similar to findings from the central California upwelling region. Trawling disturbance in deeper, upwelling regions indicates a more dramatic change in epifaunal assemblages than infauna (Engel \& Kvitek
1998, present study), while infaunal assemblages show greater change in shallow, sheltered areas (Jennings et al. 2001, Hiddink et al. 2006, Queirós et al. 2006, Hinz et al. 2009). Meta-analyses of trawl impact by Collie et al. (2000) and Kaiser et al. (2006) reveal variable responses of benthic biota with different sediment types, habitat types and fishing gear. Differences in biotic response would thus be expected from habitats as diverse as shallow, sheltered seas and outer shelf upwelling systems. A study conducted by Kaiser et al. (2000) in the Irish Sea concludes that chronic fishing has resulted in a shift from relatively sessile, emergent, high biomass species to benthic assemblages dominated by smaller-bodied infauna, and that these assemblages represent an alternative stable state. Detection of epifaunal changes with increasing trawl intensity in upwelling regions of southern Benguela and central California indicate less impacted or more resistant environments and assemblages than the shallow, sheltered North and Irish Seas where greater changes in infaunal assemblages are consistently detected.

\section{Implications for management}

Benthic assemblages of each environment and sediment type respond to trawling differently, as found in the meta-analyses of Collie et al. (2000) and Kaiser et al. (2006). Jennings et al. (2001) noted that there were different effects of trawling in 2 areas depending upon the intensity of trawling and the sediment type, with more effect on the infauna than epifauna on the more heavily trawled, muddy ground. The less heavily trawled area showed no significant effect on biomass or production. In the present study, on sandy mud substrates at $400 \mathrm{~m}$ depth, where heaviest trawling was less intense than in similar studies, epifauna provided the best indicators in response to trawling, both in

Table 7. Indicator taxa of trawling effects reported from several studies. +: increase with heavier trawling; -: decrease with heavier trawling; Echino: echinoderm; Poly: polychaete; Phoro: phoronid; Crust: crustacean. Sources: Benguela $=$ this study, California $=$ Engel \& Kvitek (1998) Irish and North Seas = Jennings et al. (2001), Queiros et al. (2006), Hiddink et al. (2006), Hinz et al. (2009)

\begin{tabular}{|c|c|c|c|c|}
\hline & & Benguela & California & Irish and North Seas \\
\hline \multirow[t]{2}{*}{ Infauna } & Increase & Ophiura (Echino) & $\begin{array}{l}\text { Ophiura (Echino) } \\
\text { Chloeia (Poly) }\end{array}$ & Prionospio (Poly) \\
\hline & Decrease & Chloeia (Poly) & & $\begin{array}{l}\text { Phoronis (Phoro) } \\
\text { Mollusca } \\
\text { Nemertea } \\
\text { Amphiura (Echino) }\end{array}$ \\
\hline \multirow[t]{5}{*}{ Epifauna } & Increase & Actinauge (Anthozoa) & & Prionospio (Poly) \\
\hline & Decrease & Spatangus (Echino) & Ptilosarcus (Pennatulacea) & Phoronis (Phoro) \\
\hline & & Echinus (Echino) & Mediaster (Echino) & Mollusca \\
\hline & & Brissopsis (Echino) & Urticina (Anthozoa) & Starfish (Echino, not \\
\hline & & Exodromidia (Crust) & Pleurobranchea (Mollusca) & significant) \\
\hline
\end{tabular}


terms of univariate indices and at the species level. Thus it appears that for this region and depth range, at current trawling intensities, benthic monitoring should include epifaunal assemblages; however, any changes in infaunal assemblages detected may indicate an altered stable state, providing useful early warning information. It is desirable to have a more rigorous sampling design with a greater number of areas and trawl intensities than was possible in the present study. The inclusion of a BACI sample design, where some areas are closed to fishing for a lengthy period, is most likely to allow better discrimination between fishing and environmental effects.

Acknowledgements. We thank the officers and crew of RV 'Dr Fridtjof Nansen' and FRS 'Ellen Kuzwayo' for their assistance with sample collections. We also thank colleagues A. Fleddum, A. Bjorgesaeter, S. Mafwila, N. Steffani and all others who assisted with sample collections, processing and identifications. We thank K. R. Clarke (Plymouth Marine Laboratory) for advice on statistical analysis and discussions on the pseudo-replication problem. J. Rogers from the Department of Geological Sciences at the University of Cape Town (UCT) assisted with sediment grain size analysis and the technical staff of the Chemistry Department at UCT conducted the organic carbon determinations. This study was funded by NORSA project 3004, and inspired by the late J. S. Gray.

\section{LITERATURE CITED}

Anderson MJ, Gorley RN, Clarke KR (2008) PERMANOVA+ for PRIMER: Guide to software and statistical methods. PRIMER-E, Plymouth

Auster P, Langton RW (1999) The effects of fishing on fish habitat. In: Benaka L (ed.) Fish habitat: essential fish habitat and restoration. Am Fish Soc Symp 22:150-187

Bianchi G, Hamukuaya H, Alvheim O (2001) On the dynamics of demersal fish assemblages off Namibia in the 1990s. S Afr J Mar Sci 23:419-428

Boyer DC, Hampton I (2001) An overview of the living marine resources of Namibia. S Afr J Mar Sci 23:5-35

Chapman P, Shannon LV (1985) The Benguela ecosystem part II. Chemistry and related processes. Oceanogr Mar Biol Annu Rev 23:183-251

Clarke KR (1993) Non-parametric multivariate analyses of changes in community structure. Aust J Ecol 18:117-143

Clarke KR, Gorley RN (2006) PRIMER v6: user manual/tutorial. PRIMER-E, Plymouth

Clarke KR, Warwick RM (2001) Change in marine communities: an approach to statistical analysis and interpretation, 2nd edn. PRIMER-E, Plymouth

Collie JS, Hall SJ, Kaiser MJ, Poiner IR (2000) A quantitative analysis of fishing impacts on shelf-sea benthos. J Anim Ecol 69:785-798

Dayton PK, Thrush SF, Agardy MT, Hofman RJ (1995) Environmental effects of marine fishing. Aquat Conserv Mar Freshw Ecosyst 5:205-232

Decker AHB (1970) Notes on oxygen - depleted subsurface current off the west coast of South Africa. Invest Rep Div Sea Fish S Afr 84:1-24

Engel J, Kvitek R (1998) Effects of otter trawling on a benthic community in Monterey Bay National Marine Sanctuary. Conserv Biol 12:1204-1214
Fairweather TP, Booth AJ, Sauer WHH, Leslie RW (2006) Spatial description of hake-directed fishing activity off the west coast of South Africa. Afr J Mar Sci 28:13-24

Field JG, Clarke KR, Warwick RM (1982) A practical strategy for analyzing multispecies distribution patterns. Mar Ecol Prog Ser 8:37-52

FIH (Fishing Industry Handbook) (2009) South Africa, Namibia and Mozambique, 37th edn. George Warman Publications, Cape Town

Folk RL (1968) Petrology of sedimentary rocks. Hemphill's, Austin, TX, p 170

Gordon DC Jr, Gilkinson KD, Kenchington ELR, Bourbonnaise C, MacIsaac KG, McKeown DL, Vass WP (2005) Summary of the Grand Banks Otter Trawling Experiment (1993-1995): effects on benthic habitat and macrobenthic communities. Am Fish Soc Symp 41:411-424

Gray JS (1974) Animal-sediment relationships. Oceanogr Mar Biol Annu Rev 12:223-261

Gray JS, Clarke KR, Warwick RM, Hobbs G (1990) Detection of initial effects of pollution on marine benthos: an example from the Ekofisk and Eldfisk oilfields, North Sea. Mar Ecol Prog Ser 66:285-299

Griffiths CL, van Sittert L, Best PB, Brown AC and others (2004) Impacts of human activities on marine animal life in the Benguela - a historical overview. Oceanogr Mar Biol Annu Rev 42:303-392

Hall SJ (1999) The effects of fisheries on ecosystems and communities. Blackwell, Oxford

Hamukuaya H, O'Toole MJ, Woodhead PMJ (1998) Observations of severe hypoxia and offshore displacement of Cape hake over the Namibian shelf in 1994. S Afr J Mar Sci 19:57-59

Hiddink JG, Jennings S, Kaiser MJ, Queirós AM, Duplisea DE, Piet JG (2006) Cumulative impacts of seabed disturbance on benthic biomass, production, and species richness in different habitats. Can J Fish Aquat Sci 63: 721-736

Hinz H, Prieto V, Kaiser M (2009) Trawl disturbance on benthic communities: chronic effects and experimental predictions. Ecol Appl 19:761-773

Hurlbert SH (1984) Pseudoreplication and the design of ecological field experiments. Ecol Monogr 54:187-211

Jennings S, Kaiser MJ (1998) The effects of fishing on marine ecosystems. Academic Press, London, p 203-314

> Jennings S, Pinnegar JK, Polunin NVC, Warr KJ (2001) Impact of trawling disturbance on the trophic structure of benthic invertebrate communities. Mar Ecol Prog Ser 213: $127-142$

Kaiser MJ, de Groot SJ (2000) The effects of fishing on nontarget species and habitats. Blackwell, Oxford

Kaiser MJ, Edwards DB, Armstrong PJ, Radford K, Lough NEL, Flatt RP, Jones HD (1998) Changes in megafaunal benthic communities in different habitats after trawling disturbance. ICES J Mar Sci 55:353-361

Kaiser MJ, Ramsay K, Richardson CA, Spence FE, Brand AR (2000) Chronic fishing disturbance has changed shelf sea benthic community structure. J Anim Ecol 69:494-503

Kaiser MJ, Collie JS, Hall SJ, Jennings S, Poiner IR (2002) Modification of marine habitats by trawling activities: prognosis and solutions. Fish Fish 3:1-24

> Kaiser MJ, Clarke KR, Hinz H, Austen MCV, Somerfield PJ, Karakassis I (2006) Global analysis of response and recovery of benthic biota to fishing. Mar Ecol Prog Ser 311:1-14

> McConnaughey RA, Mier KL, Dew CB (2000) An examination of chronic trawling effects on soft-bottom benthos of the eastern Bering Sea. ICES J Mar Sci 57:1377-1388

MFMR (Ministry of Fisheries and Marine Resources) (2005) 
Demersal trawl Catch Per Unit Effort (CPUE) data. Ministry of Fisheries and Marine Resources, Namibia

Monteiro PMS, van der Plas AK (2006) Low oxygen water (LOW) variability in the Benguela system: key processes and forcing scales relevant to forecasting. In: Shannon LV, Hempel G, Malanotte-Rizzoli P, Moloney C, Woods J (eds) Benguela: predicting a large marine ecosystem. Large Marine Ecosystems, Vol 14. Elsevier, Amsterdam, p 71-90

Oksanen L (2001) Logic of experiments in ecology: is pseudoreplication a pseudoissue? Oikos 94:27-38

Payne AIL, Punt AE (1995) Biology and fisheries of South African Cape hakes (M. capensis and M. paradoxus). In: Alheit J, Pitcher TJ (eds) Hake: biology, fisheries and markets. Chapman \& Hall, London, p 15-47

Queirós AM, Hiddink JG, Kaiser MJ, Hinz H (2006) Effects of chronic bottom trawling disturbance on benthic biomass, production and size spectra in different habitats. J Exp Mar Biol Ecol 335:91-103

Submitted: April 27, 2010; Accepted: November 24, 2010
Sokal RR, Rohlf FJ (1969) Biometry. Freeman, San Francisco, CA

Thrush SF, Hewitt JE, Cumings VJ, Dayton PK and others (1998) Disturbance of the marine benthic habitat by commercial fishing: impacts at the scale of the fishery. Ecol Appl 8:866-879

Warwick RM, Clarke KR (1991) A comparison of some methods for analyzing changes in benthic community structure. J Mar Biol Assoc UK 71:225-244

Watling L, Norse EA (1998) Disturbance of the seabed by mobile fishing gear: a comparison to forest clearcutting. Conserv Biol 12:1180-1197

Wilkinson S, Japp DW (2005) Description and evaluation of hake-directed trawling intensity on benthic habitat in South Africa. Fisheries and oceanographic support services CC, Cape Town

Zar JH (1999) Biostatistical analysis, 4th edn. Prentice Hall Englewood Cliffs, NJ

Proofs received from author(s): March 25, 2011 